\title{
Contextuality in the Russian language
}

\author{
Igor G. Miloslavsky \\ Lomonosov Moscow State University \\ 31 Bldg. a Lomonosov Str., 119192, Russia
}

\begin{abstract}
The modern scientific paradigm of linguistics that replaced comparative historical and linguistic-centric paradigm is focused on the relationship between language and reality which is inherently asymmetric in nature. In this situation, the problem of an accurate and complete mutual understanding of the participants of communication becomes more and more urgent. This problem considered in the framework of cultural studies suggests the division of cultures into high context cultures, i.e. those where the behavior of communication participants does not directly express their goals and intentions, and low context cultures, implying direct and frank manifestations of those intentions. The author applies the idea of high and low contextuality to the Russian language, setting the task of identifying those typical manifestations of Russian discourse in which the linguistic signs show a high dependence on the situational and verbal context, and in this way, by virtue of the language structure, cause difficulties for mutual understanding. From this point of view, the study investigates the polysemy of Russian words and grammatical forms, as well as the conditions in which their unambiguous understanding is or is not achieved. It emphasizes the insufficiency of merely stating the possibility of several solutions and the need for algorithms that provide the only (or not the only) correct solution. The author sees another obstacle for successful communication in hyperonyms that do not have a distinct hyponymic content for each participant of communication. The third obstacle is the omission of the verbal designation of modifying and / or substantial characteristics of reality. The article emphasizes that those who speak Russian, in principle possessing the resources necessary for overcoming these difficulties, seek to use them effectively only in certain specialized areas (science, sports, trade) and do not care about the maximum adequacy of language units and reality in everyday and political discourse. In conclusion, the article describes how to take into account the noted features of the Russian language when consciously learning Russian as a native language, as well as when teaching it as a foreign language.
\end{abstract}

Keywords: polysemy, formally unexpressed meanings, hyperonyms, context, situation, vocabulary, grammar

\section{For citation:}

Miloslavsky, Igor G. (2019). Contextuality in the Russian language. Russian Journal of Linguistics, 23 (3), 731-748. doi: 10.22363/2312-9182-2019-23-3-731-748. 
Научная статья

\title{
Контекстуальность в русском языке
}

\author{
И.Г. Милославский \\ Московский государственный университет имени М.В. Ломоносова \\ Ленинские горы, 1, стр. 13-14, Москва, 119991, Россия
}

\begin{abstract}
Аннотация
Современная научная парадигма языкознания, пришедшая на смену сравнительно-исторической и лингвоцентрической парадигме, ставит в центр внимания соотношение между языком и действительностью, которое по своей природе является асимметричным. В этой ситуации все более и более актуальной становится проблема точного и полного взаимного понимания участников коммуникации. Эта проблема, рассматриваемая в рамках культурологии, предлагает деление культур на высоко контекстуальные, т.е. такие, где поведение участников коммуникации не прямо выражает их цели и намерения, и низко контекстуальные, предполагающие проявления прямые и откровенные. Автор прилагает идею о высокой и низкой контекстуальности к русскому языку, ставя перед собой задачу выявить те типовые проявления русского дискурса, в которых составляющие сообщение языковые знаки проявляют высокую зависимость от контекста, ситуативного и вербального, и именно таким образом уже в силу устройства самого языка создают трудности для взаимопонимания при общении на нем. Под этим углом зрения рассматривается многозначность русских слов и грамматических форм, а также те условия, в которых достигается или не достигается однозначное их понимание. Подчеркивается недостаточность констатации возможности нескольких решений, но необходимость алгоритмов, дающих единственное (или не единственное) правильное решение. Другую помеху для успешной коммуникации автор видит в гиперонимах, не имеющих для каждого участника коммуникации внятного гипонимического наполнения. Третье препятствие состоит в опущении вербального обозначения некоторых модификационных и/или субстанциональных характеристик действительности. В статье подчеркивается, что говорящие по-русски, принципиально располагая необходимыми для преодоления этих трудностей ресурсами, стремятся их эффективно использовать лишь в некоторых специальных областях (наука, спорт, торговля) и нимало не заботятся о максимальной адекватности единиц языка и действительности в бытовом и политическом дискурсе. В заключение в статье говорится о том, как следует учитывать отмеченные особенности русского языка при сознательном школьном обучении русскому языку как родному, а также при обучении РКИ.
\end{abstract}

Ключевые слова: многозначность, формально не выраженные смыслы, гиперонимы, контекст, ситуачия, лексика, грамматика

\section{Для цитирования:}

Милославский И.Г. Контекстуальность в русском языке // Russian Journal of Linguistics. 2019. T. 23. No 3. C. 731-748. doi: 10.22363/2312-9182-2019-23-3-731-748.

Князь был немного ограничен и потому любил в словах точность Ф.М. Достоевский «Подросток»

\section{1. Контекстуальность языка в современной лингвистической научной парадигме}

Считается, что языкознание (как наука и не как практическое знание языков) началось как сравнительно-историческое. Предельно упрощая дело, можно видеть цель этой научной парадигмы в том, чтобы восстановить праязык, к которому восходят современные языки (Алиференко 2014). На пути к этой цели казалось, 
что для некоторых групп языков такая задача легко достижима. Например, для русского, болгарского, чешского, польского, или немецкого, датского, шведского, или для французского, итальянского, испанского и португальского и т.П. При этом выяснилось, что общий праязык существовал не только для приведенных выше групп европейских языков, но и сами они являются продолжением более древнего так наз. индоевропейского праязыка, к которому восходят санскрит, а также некоторые другие, хотя и далеко не все, языки Европы и Азии. Объединяющая все сравнительно-историческое языкознание цель (Доброхотов 2010) - восстановление праязыка и уяснение сложных путей его развития к современным языкам - закономерно создала генетическую классификацию языков. Известные результаты такой классификации позволяют справедливо характеризовать, например, русский язык как один из языков славянских и - шире - индоевропейских. Нередко употребляющие эти характеристики забывают формально не выраженные в таком случае за их очевидностью слова «по происхождению».

Смена лингвистической научной парадигмы с исторической на синхронную привела к кардинальному изменению целей лингвистики как науки (Алпатов 2005). Эта цель предстала в виде установления правил и закономерностей, действующих в каждом конкретном языке (Соссюр 2004). Уклонимся от обсуждения вопроса о том, как поворот в языкознании от диахронии к синхронным связям и отношениям коррелирует со сменой парадигм и во многих других гуманитарных науках и как это связано с общественными запросами. Лозунг «изучать язык ради самого языка» привел и к смене основания для классификации языков. Это основание из генетического переместилось в сторону формальной техники, реализуемой конкретными языками или группами языков. В первую очередь классификаторы сосредоточились на противопоставлении аналитических языков и языков флективных, делая упор на большую или меньшую роль в языке форм словоизменения, на типы парадигм, а следовательно, на флексию, на моносемность или многосемность флексий.

В результате этих наблюдений мы можем, например, утверждать, что русский язык по преимуществу флективный, хотя в нем есть и элементы аналитизма (в отличие от преимущественно аналитического, хотя и с элементами флективности английского) (Панов 1963). При этом в русском языке флексии по преимуществу многосемные (в отличие от тюркских языков).

«Семантический взрыв», произошедший в языкознании в середине прошлого века, перевел внимание с самодовлеющего изучения устройства языков на вопрос о соотношении языка и отражаемой им действительности, включив язык в область теории познания и социального взаимодействия между людьми, пользующимися языком, т.е. в область культуры. Как известно, современная культурология также пытается классифицировать многообразные культуры прежде всего как типы социального поведения и взаимодействия людей по разным основаниям (мужские - женские, коллективистские - индивидуалистические, урбанистические сельские и даже восточные - западные и т.п.) (Лотман 1979, Флиер 2002). Среди этих многообразных оснований классификаций (ср. с ограниченным числом оснований для классификации языков) выделяется деление культур на вы- 
соко и низко контекстуальные (Hall 1990). При этом в качестве основания выступает количество информации, формально реализуемой в коммуникации: в высоко контекстуальных культурах количество такой информации меньше, в низко контекстуальных - больше. Другими словами, в низко контекстуальных культурах ценность каждого формального, в том числе и вербального, компонента больше, а в высоко контекстуальных - меньше. Ценность в этом случае рассматривается, во-первых, как адекватность и, во-вторых, как релевантность сообщений по отношению к действительности, к положению дел. Обе эти характеристики, несколько огрубляя дело, могут быть успешно соотнесены с действительностью лишь с учетом разнообразных типов контекстов в высоко контекстуальных культурах и обычно не требуют контекстного погружения в низко контекстуальных культурах (Балачандран 2016). В качестве полярных при таком взгляде примеров выступают американская культура, где да значит «да», а нет значит «нет», и японская, где нет вообще не употребляется, а да может быть окружено таким контекстом, который его значение едва ли не опровергает. Русская культура по обсуждаемому параметру занимает промежуточное положение, хотя и ближе к высоко контекстуальным, (что не редкость и в иных классификациях): ср. русское решительное «нет» и $\partial а$, но..., где следующее после но обычно зачеркивает само предшествующее $\partial a$.

В процессе коммуникации взаимодействуют, более или менее успешно, отправитель и получатель сообщения. Успешность коммуникации обеспечивается за счет фонда общих знаний участников о жизни вообще и о конкретной ситуации общения, в частности. Однако не следует забывать, что кроме самих участников коммуникации важную роль в ней играет само средство коммуникации, язык, на котором она осуществляется. И именно свойства языка могут или способствовать или препятствовать успеху коммуникации (Roy 2010). Очевидно, что чем более высококонтекстуальным является язык коммуникации, тем более трудные задачи приходится решать реципиенту. Для точного понимания в этих случаях он должен решать не только одноходовые задачи по соотнесению языкового знака с действительностью, но задачи двуходовые, когда из некоторого множества возможных значений следует выбрать именно то, которое представлено в тексте, созданном производителем речи. И сам производитель речи должен стремиться не только адекватно воплотить свои представления о действительности, но и предусмотреть те трудности, которые могут возникнуть у адресата и постараться избегнуть их. Подобную же «заботу об удобстве» получателя информации реализует соблюдение орфографических и/или орфоэпических правил. Ценность этих правил именно в облегчении усилий получателя информации, который не должен отвлекаться на отклонения от принятых норм и может (должен!) сосредоточиться исключительно на содержательной стороне сообщения (Пешковский 1959).

Предмет статьи - оценка роли контекста не в коммуникативном поведении говорящих по-русски, но в самом устройстве русского языка. Часто носитель китайского языка затрудняется с ответом на вопрос, что же означает какое-либо произнесенное по-китайски слово. В русском такая ситуация скорее редкость, хотя в толковых словарях русского языка очень мало статей, правая часть которых 
не состояла бы из 1., 2., 3. и т.д. (Зализняк 2006, Иомдин 2014, Ольховская 2015, Песина 2005, Navigli 2009). Главная задача статьи состоит в том, чтобы представить те типовые случаи, когда без привлечения контекста невозможно однозначно понять значение слов и форм, предложений и текстов на русском языке. Также предпринимается попытка осмыслить те последствия, которые вытекают из соответствующих наблюдений, для практики использования и преподавания русского языка как родного и как неродного.

\section{2. О преодолеваемой и не преодолеваемой контекстом многозначности слов}

Банальным является утверждение «Контекст устраняет полисемию». Однако эта банальность редко уточняется в связи с тем, что само слово контекст обычно подразумевает и сам законченный фрагмент текста со всеми его словами и формами, и общую ситуацию, которая описывается в конкретном тексте (Кобрицов 2004; Добров, Лукашевич 2007). Так, например, слово ворота и без словесного окружения в репортаже о футбольном матче воспринимается однозначно как «воображаемая плоскость, ограниченная в длину и высоту двумя столбами и перекладиной поверх их, попадание за которую есть цель игры», в отличие от значения того же слова в ситуациях, связанных с обозначением местности, где оно обозначает «возможность сквозного проезда» (ср. также топонимы Красные (Покровские, Спасские и др.) ворота). Продолжая футбольную тему (без указания на словесное окружение!), назову еще бровка как «край футбольного поля» (ср. с ситуацией в парикмахерской), судья и защчттник (ср. с ситуацией судебного процесса), удар («по мячу») и удар (в ситуации физического и/или морального конфликта людей или групп людей) и т.д. и т.п. Даже различая словесный и ситуативный контексты, приходится констатировать, что не все контексты обоего типа непременно преодолевают полисемию (и омонимию). Предложение $\mathrm{Mbl}$ долго искали и, наконеи, нашли ключ оставляет вопрос о значении слова ключ открытым. Если же известно, что это предложение относится к ситуации описания загородной прогулки, то очень высока, хотя и не 100 \%, вероятность понимания «источник воды». Такая вероятность полностью исключается в описании любых урбанистических ситуаций. Эта очевидность достаточно хорошо исследована (не на материале русского языка), в аспекте вербальных контекстов, как способствующих пониманию А, так и исключающих понимание А. Однако признавая влияние обоих типов контекста на точность понимания, не следует забывать о таких случаях, когда такая однозначность понимания не достигается (ср. с недостаточностью улик, определяющих преступника из ряда подозреваемых). Попробуем конкретнее рассмотреть этот вопрос, двигаясь от некоторых многозначных слов.

Государство. Это слово употребляется в трех значениях. В качестве обозначения «страны» (границы государства, государства Европь). В качестве обозначения «устройства повседневной жизни людей» (феодальное государство, государство в государстве). И в качестве обозначения организованной группы лиц, осуществляющих властные функции (напомню ленинское определение государства как «аппарата насилия одного класса над другим»). Например, из пред- 
ложения $О$ социильно не защищенных должно позаботиться государство неясно, имеется ли в виду «устройство» (как саморегулирующаяся система) или «власть». Конституция - основной закон государства - государства как «страны» или как «устройства»? (Наверное, «устройства», поскольку в одной и той же стране конституция может меняться, однако возможно и «страны», потому что «устройство» не всегда точно отражается в конституции, а также может быть более или менее сходным в разных странах). Политика, враждебная интересам государства интересам «страны», интересам «устройства» или «власти»? Если в этих расхожих контекстах возможны разные толкования, то успех коммуникации находится в зоне большого риска, поскольку осмысление одного и того же слова отправителем и получателем коммуникации может и совпадать, и не совпадать. Добавлю, что при понимании государства как «власти» остаются неясными те конкретные лица, которые имеются в виду. А при понимании государства как «устройства» в таком же положении находятся те институты как элементы структуры, которые входят в «устройство». Уход от конкретики в этих случаях демонстрируют также такие выражения, как, например, в Кремле считают, Бельй дом возражает, Париж согласен на переговоры и т.П., где подразумевается «власть», однако это обозначено весьма размыто (см. об этом ниже).

Культура. Слово культура употребляется в русском языке в нескольких значениях. В качестве основных можно выделить четыре случая. «Бытовая культура» как соблюдение определенных норм в повседневной жизни, санитарных, гигиенических и пр., поддерживающих физическое здоровье человека, удовлетворяющих его физиологические потребности. Другое значение - это «культура духовная», т.е. культура в отношениях между людьми в разных коллективах и обстоятельствах, в поведении, в коммуникации, во внимании не только к самому себе, но и к другим, живым, умершим и еще не родившимся. Этим двум связанным между собой значениям противостоит культура как обозначение «высоких достижений человечества в художественной области», в музыке и поэзии, живописи и литературе и пр. (Художественная культура тесно связана с духовной, но также часто соприкасается с бытовой в таких, например, областях, как архитектура и дизайн). При этом разнообразные результаты, достигаемые художественной культурой, равно как и целенаправленные усилия к этим результатам ведущие, требуют своих организационных и вполне материальных структур, музеев и киностудий, театров и училищ и др. И это разнообразное хозяйство также называют культурой, наряду с образованием, здравоохранением, например, предусматривая на нее бюджетные расходы. Поэтому, когда речь идет, например, о министерстве (министре) культуры, это можно понимать и как «высокие достижения», и как «хозяйство, связанное с созданием и сохранением этих достижений». Видимо, необходимость различения этих двух значений отразилась, пусть и не лучшим образом, в противопоставлении деятеля культуры (режиссер, художник, артист и пр.) и работника культуры (служащий соответствующего министерства, музея, театра и пр.).

Очевидно, что в словосочетаниях типа средневековая культура, немецкая культура и т.п. культуру можно понимать и как бытовую, и как духовную, и как 
художественную. В связи с этим хочу привести рассказ А.А. Зализняка о разговоре с С.С. Аверинцевым, читавшим тогда курс русской духовности. «Аверинцев сказал: „Область, к которой относятся мои занятия, — не наука и не искусство; но она не менее интересна для человека, чем наука и искусство. Человечество, однако, не выработало для нее отдельного имени, и за неимением такового ее относят к науке...“ А.А. Зализняк добавляет: «Его слова произвели на меня тогда очень сильное впечатление - своей ясностью и бесстрашной прямотой» (Зализняк 2018).

Народ. У этого слова можно выделить три значения. Первое обозначает население какой-либо страны - государства (см. выше) или некую этническую общность людей, совсем не обязательно совпадающую с государственной принадлежностью (ср. словосочетание титульная нация, обозначающее такое совпадение). Вообще невнятное разграничение гражданства («подданства») и нащиональности («этнического происхождения») породило очень много проблем для русского языка особенно в середине прошлого века, когда, по мнению официальных властей, сформировалась «новая культурно-историческая общность людей - советский народ». Обсуждение этих очень важных для русского языка вопросов, связанных с не всегда гармоничным взаимодействием между политическим и бытовым дискурсом увело бы нас в сторону от обсуждаемой проблемы.

Другое значение слова народ — это «основная трудовая масса населения». Именно в этом значении это слово употреблено в революционной песне: «Вышли мы все из народа, дети семьи трудовой». Замечу, что это значение внятно выражается словосочетанием простой народ и словом простонародье («Всей по наследству перешедшей плотью, всем обликом, которым дорожу, к иирокому в плечах простонародью я от рождения принадлежу», - писал поэт Евгений Винокуров). Подобная же утрата определяющего прилагательного произошла в начале прошлого века со словосочетанием сознательный рабочий, когда оно превратилось по форме просто в рабочий, сохранив положительный оценочный компонент от прежнего значения словосочетания. И, наконец, третье значение - «люди, группа людей». Именно в этом значении это слово употребляется в сказке Леонида Филатова «Про Федота-стрельца...»: «Там собрался у ворот этот (как его?) народ...». Хотя вполне возможно видеть здесь и значение, отмеченное выше как второе.

Благодаря лишь широкому контексту пушкинского Бориса Годунова в словосочетании Народ безмолвствует следует видеть значение 2. В более узком контексте возможно и понимание 3.

Множественность значений весьма употребительного слова народ в словосочетании «весь народ» породило справедливую реплику Андрея Платонова: «Без меня народ не полный». Современные идеологи продолжают эксплуатировать многозначность слова народ, пытаясь внедрить содержательно невнятное словосочетание «глубинный народ». Автор не задается неизбежным в таком дискурсе вопросом, чем же глубинный народ отличается от народа поверхностного и просто от народа. 


\section{3. Гиперонимы без ясных гипонимов}

Другое проявление необходимости контекста для внятного понимания написанного/произнесенного находим среди гиперонимов с неясными гипонимами. События, происшествия, мероприятия, политика, свойства, специфика, возможности, достижения, поведение, природные явления, общественные интересы, государственная безопасность, качество населения и мн. и мн. др. - все эти обозначения, более или менее ясные по своей когнитивной сути, оставляют весьма невнятным конкретный объем покрываемых таким именованием понятий.

Постараюсь продемонстрировать эти обстоятельства на примере слова цееннсти. Очевидно, что само это слово представляет пример регулярной многозначности, соединяющей физическое и нравственное (трогать за душу и за руку, теплая вода и чувства, высокие потолки и мысли, чистоту соблюдать и хранить), что более или менее легко различается благодаря контексту (см. выше). В данном случае речь о другом, о том, какие же именно нравственные представления и нормы поведения общество воспринимает как ценные (Inglehart 2018). (Замечу, что при этом непременно возникает необходимость признать некоторые характеристики и нормы не ценными, а следовательно, требуется обосновать и реализовать такое деление).

Принято считать, что основные моральные ценности сформулированы в 10 христианских заповедях, однако едва ли все из них (как, например, заповедь о субботе) подразумеваются употребляющими сегодня слово изенности. С другой стороны, обязанность заботиться (и материально, и морально!) о детях не выступает в числе заповедей. Равно как и внимание к больным, слабым, нуждающимся, проявление которого есть самоё суть христианства, не отмечено специально в заповедях, но представлено евангельскими притчами.

В связи с невнятным наполнением содержания слова ценности не могу не вспомнить показанную по отечественному ТВ встречу Маргарет Тэтчер с ведущими советскими журналистами. Когда один из них упомянул преимущества сочииализм, Тэтчер буквально закричала What advantages?! и, не получив внятного ответа, довела беседу до полного разгрома оппонентов.

Вопрос о соотношении гиперонимических и гипонимических обозначений, будучи одним из фундаментальных и в теории познания, и в лингвистике, в русистике никогда не рассматривался как весьма актуальный. Хотя и привлекал внимание исследователей прежде всего в связи с попытками создания научно-терминологических систем (Лотте 1961). Между тем очевидно, что предложение Соловей разливается в терновнике значительно информативнее, чем такое же по количеству слов предложение Птица поет в кустах. Как очевидно и то, что для ценителя тонких чувств предпочтительнее первое, а для стремящегося к обобщениям ученого, орнитолога или ботаника, ценнее второе.

Не могу не обратить внимание, что современный русский дискурс (sic!) очень активно использует гиперонимические обозначения. В детстве я никак не мог понять, что же я должен делать, когда человек с плаката призывал и меня бороться за мир. Или соблюдать / не нарушать правила, суть которых оставалась для меня 
весьма невнятной. Помогали справиться с ситуацией И. Ильф и Е. Петров с их призывом «перестать бороться за чистоту, а начать подметать». Размытые невнятные рекомендации широко представлены и в быту, где советы типа быть «аккуратным (внимательным)», «не тратить напрасно здоровье (деньги)», «стараться» и т.п. выражают лишь участливое отношение к судьбе адресата, никак не снабжая его какими-либо конкретными рекомендациями о том, как же обеспечить эту счастливую судьбу.

\section{4. Формально не выраженные значения, модификационные и субстанциональные}

Кроме слов со множеством значений, кроме гиперонимов с неясным гипонимическим наполнением, часто даже и не проясненным благодаря контексту, следует выделить еще один случай семантической неопределенности, преодолеваемой и не преодолеваемой контекстом. Я имею в виду формальное отсутствие модификатора, открывающее возможность неоднозначного понимания, каковое также может быть, а может и не быть преодолено благодаря контексту.

Известный диалог Фамусова с Молчалиным иллюстрирует именно такой случай: Шел в комнату - попал в другую... - Попал или хотел попасть? И грозный царь спрашивал купца Калашникова: «Вольной волею или нехотя ты убил моего верного слугу?...» В самом деле в русском языке есть немало глаголов, которые могут обозначать и целенаправленное действие, и действие случайное, непроизвольное: Поскользнулся и упал (случайно), но Упал - отжался (на занятии физкультурой) называет уже не случайное падение.

Проснулся - сам или потому, что разбудили? Только контекст может дать ответ на этот вопрос (Проснулся от удара грома), а без подобного контекста вероятны оба толкования. Это совершенно ясно на фоне выздоровел - вылечили, лег - положили, встал - подняли и др. (Гордиевская 2018). И многие глаголы с -ся также оставляют открытым вопрос о том, кто (что) является источником состояния: рассмеялся, удивился, рассердился и др. сам или по внешней причине? Ср. также расnад CCCP («сам») и развал СССР («сам» или «в результате чьих-то усилий») (см. ниже).

Обозначения, предполагающие разные модификаторы, представлены не только в глаголах. Куртка - одежда для улицы, т.е. как плаш, пальто, или для дома, т.е. как пиджак, кофта? Чайник - сосуд определенной формы для кипячения воды или для заварки? Только контекст (например, железнылй или фарфоровылй может прояснить этот вопрос). Разумеется, при наличии некоторых знаний о материалах и о процедуре приготовления чая (ср. англ. tea-pot и tea-kettle). И даже слово человек, обозначая и мужчину, и женщину, только благодаря контексту может (или не может) уточнить, кто же имеется в виду, мужчина или женщина, мальчик или девочка.

Формально отсутствовать в речи, хотя и присутствовать в сознании и для реципиента, и производителя речи - могут не только модификационные характеристики. Знаменитая фраза 3.Н. Гиппиус «Если надо объяснять, то не надо объяснять» несмотря на не замещенную при глаголе позицию объекта, очень 
внятно описывает невозможность эффективной коммуникации специалиста с профаном, интеллектуала с дикарем, душевно тонкого человека - с грубым и примитивным... (Известно, что при различии в компетенции участников коммуникации она может быть успешной, только соответствуя нижнему уровню).

У больного температура (> N), В раю, конечно, климат, зато в аду общество («хороший»), женщчна в возрасте («большом»), Карету мне, карету! («дайте»), моя бывшая («жена») - и другие подобные примеры подтверждают тот факт, что многие русские предложения значат (и для продуцента, и для реципиента) больше, чем простая сумма тех слов и форм, из которых это предложение состоит. Весьма широкое использование в русском дискурсе различных прецедентных текстов и их персонажей, знакомых и производителю, и реципиенту, также позволяет говорить о проявлении высокой контекстуальности русского языка. Впрочем, здесь мы уже выходим за пределы языка и собственно речевой деятельности, в область, которую за неимением лучшего обозначения принято именовать «фондом общих знаний собеседников», которые непременно следует отличать от знания о конкретных ситуациях как самого общения, так и предмета речи (см. об этом ниже).

В связи с этим особого внимания заслуживают формально не выраженные значения, представленные в русских относительных прилагательных разного типа. Ср., например, притяжательные прилагательные медвежья берлога («где живет...») и медвежья походка («такая, как у...»), осиное гнездо, осиный укус и осиная талия, лебединый крик, любовь, песня. Правда, у притяжательных прилагательных в русском языке, выделяемых таким образом исключительно по типу оформления парадигмы склонения, подобная многозначность невыраженных компонентов значения вещь довольно редкая. Здесь в качестве невыраженного формально компонента значения преимущественно выступает «принадлежащий, обладающий». Зато собственно относительные прилагательные обладают весьма широким набором формально не выраженных значений, характеризующих тот характер «отношений», которые существуют между значениями определяемого существительного и корня определяющего прилагательного. Ср. стальная иголка и воля, дачная постройка и жизнь, итальянский полдень и костюм и мн. др.

Такая же проблема возникает с прилагательным контекстуальный — «имеющий какие-то отношения с определяемым словом» и его синтаксическим дериватом контекстуальность. Контекстуальность культуры (и языка) можно понимать и как «зависимость от контекста» (относительно бо́льшая или меньшая), и как «обязательное требование к контексту для успешной коммуникации» (в большем или меньшем объеме) (Ларина 2017). Ср. также деревенский дом - «находящийся в...» и «такой, как в...», университетский учебник — «созданный в...» и «предназначенный для...» и мн. др.

\section{5. Контекстуальная зависимость значения грамматических показателей}

Высокую зависимость своей семантики от контекста обнаруживают в русском языке грамматические характеристики и, в частности, флексии. Даже такие сугубо сочетаемостные по своей природе грамматические характеристики существитель- 
ных как род и одушевленность в некоторых контекстах приобретают семантическую ценность (Зализняк 1967). Например, ужасный невежа - ужасная невежа (мужской и женский пол); наш врач - наша врач (пол неизвестен - женский пол); падающего толкни - падающее толкни (лицо - предмет, явление). Разнообразие типов склонения и многочленность падежной системы также не позволяют без обращения к контексту определить падежную характеристику многих существительных (столу - сестру, сливки - в тиши - у земли, крестьяне - в небе к стене и др.), а тем более номинативную ценность конкретной грамматической характеристики (дать брату - брату скучно, нет стены - край стены и др.).

Хорошо известна контекстная зависимость грамматических форм числа существительных, где в качестве воздействующего контекста могут выступать разные факторы, от лексического значения слова (сливки - волки, ворота - профессура - знамена и др.) до общего фонда знаний коммуникантов (На стройку привезли кирпич; Водитель, уступи дорогу пешеходу!) (Ляшевская 2004). Также хорошо известны различные значения конкретных глагольных характеристик наклонения, времени и даже лица. Не могу не заметить, что все эти контекстуальные изменения обычно иллюстрируются отдельными примерами, а конкретные условия, в каждом случае определяющие ту или иную семантическую трансформацию, исчерпывающим образом, насколько мне известно, не выявлены. Эта задача в условиях существования корпуса русского языка (с соответствующей разметкой!) представляется реально выполнимой. А практическая важность такого решения актуальна не только для рецепции, но и в связи с необходимостью обеспечить продуктивные речевые действия на русском языке. Напомню, что цель таких действий - никогда не употребление определенной грамматической формы, но воплощение определенного содержания, которое часто выражается по-разному именно в конкретном контекстуальном окружении (Милославский 2018).

Особого внимания в связи с вопросами контекстуальности русского языка заслуживают вопросы о безличных глаголах типа спится, работается, и о страдательных формах глаголов с полной парадигмой. Как известно, субъект в этих случаях не только выражается нестандартно, т.е. не именительным, но либо дательным, либо творительным падежом, но может и вообще опускаться: считается, что... решение принято; вопрос обсуждается и др. Таким образом возникают контексты, дающие широкий простор для предположений реципиента о том, кто (что) же именно есть производитель действия (носитель состояния) (Падучева 2012). Весьма заманчиво видеть во всех этих случаях в качестве производителя некую сверхъестественную силу, что представляет большой интерес для классификации языков по параметру «отношение к власти», нередко выступающему в качестве основания для классификации культур.

На фоне артиклевых языков очевиден преимущественно контекстуальный способ выражения определенности - неопределенности лица, предмета и явления в русском языке (Виноградов 1990). Напомню, что русский язык располагает необходимым и достаточным арсеналом средств и для выражения определенности (этот, тот самый, упомянутый, новейшее нелитературное конкретный и др.), и для выражения неопределенности (какой-то, некий, один, всякий и др.). Дело 
лишь в том, что в отличие от артиклевых языков, этот параметр в русском языке вовсе не обязателен для выражения и таким образом, будучи опущен, дает реципиенту простор для интерпретаций, регулируемых лишь различными типами контекстуального воздействия (см. выше).

Подобная же свобода интерпретации в значительной степени характеризует и временные формы русского глагола. Так, например, употребление личных форм настоящего времени дает основание считать их вневременными, а следовательно, их оппозиции прошлому и будущему — привативными со всеми вытекающими отсюда последствиями для осмысления настоящего времени (Виноградов 1972). В русском языке вовсе не обязательно обозначать последовательность внутри прошлых и внутри будущих действий. Это, как и в случае с артиклями, можно легко сделать (после того, как; сначала, сперва, потом, после и др.), но можно и не делать, полагаясь на сообразительность (и доверчивость?) реципиента. Право, заслуживающее внимания свойство языка (мышления, души?)!

Не могу также не отметить, что глаголы несовершенного вида также находятся в привативной оппозиции к глаголам совершенного вида. Если у глаголов совершенного вида непременно есть указание либо на однократность действия (сказал, толкнул, поцеловал, позвонил и др.), либо на его результативность (построил, написал, выучил и др.), либо они допускают обе интерпретации (встал, выбрал, решил и др.), то соответствующие глаголы несовершенного вида вовсе не сообщают о действиях многократных и/или безрезультатных (Милославский 2015). Говорил, толкал, целовал, звонил - сколько раз, неизвестно, строил, писал, учил просто ничего не сообщают о результате этих усилий. Ср. звонил (по телефону) - позвонил - дозвонился и встал сразу - с трудом, решил тотчас - после раздумий; звонил один раз и много раз, однажды говорил и всегда говорил и т.п. Очевидно, что во всех этих случаях именно контекст способен добавить соответствующую модификационную характеристику, либо, оставаясь никак не выраженной, она оставляет реципиенту возможность разных интерпретаций.

Добавлю еще и так наз. нулевую связку в простом предложении и деепричастные обороты, сообщающие явно лишь о меньшей значимости называемого ими действия. Между тем между обоими действиями могут существовать и другие содержательные связи: ср. Подъезжая под Ижоры, я взглянул на небеса, И воспомнил ваши взоры, ваши синие глаза (одновременность) и Решась кокетку ненавидеть, кипящий Ленский не хотел пред поединком Ольгу видеть (причина и следствие). Очевидно, что характер отношений между «основным» и «побочным» действиями, формально никак не выраженный, определяется исключительно контекстом, причем не всегда однозначно. То же самое относится и к различным бессоюзным сложным предложениям: ср. Сыр выпал - с ним была плутовка такова (последовательность) и Проголодаешься - так и хлеба достать догадаешься (условие) и мн. др.

\section{6. Тенденция к высокой или низкой контекстуальности}

Наблюдения за изменениями в русском языке конца прошлого - начала нынешнего века свидетельствуют о разнонаправленных тенденциях, действующих в нем по параметру «контекстуальность» (Валгина 2001, Богданова 2018). 
Одна тенденция состоит в том, что многозначность, а следовательно, и контекстуальность растет. Появление (или открытие) новых феноменов в жизни не порождает новых номинаций, но включается как одно из значений в уже имеющиеся слова. Так, например, произошло с именованиями прежде только «мужских» профессий и должностей. Появление в этом амплуа женщин расширило число значений у таких, например, слов, как доктор, врач, инженер, агроном, декан, директор, добавивших к своим возможным значениям еще и «Женщина, имеющая такую профессию (должность)». При другой интерпретации этого явления прежнее значение «мужчина, имеющий такую профессию (должность)» трансформировалось в «лицо...» (см. об этом выше 1.3). Другие возможности отразить в языке произошедшие гендерные социальные изменения оказались не слишком успешными. Либо по причине столкновения с именованиями жен по мужу (губернаторша), либо по причине наличия отрицательной оценки (врачиха), либо в силу ограниченности синтагматических возможностей (врач пришла, хорошая врач только в именительном падеже). Добавлю, что во всех таких случаях оппозиция по отношению к немодифицированному обозначению оставалась привативной, т.е. контекстуальная зависимость у него сохранялась.

Новейшим примером той же тенденции выступает слово коррупция, которым обозначаются любые способы использования служебного положения для удовлетворения личных потребностей. Это именование применяется к самым различным таким действиям (ср. взяточничество, вымогательство, насилие, связи с преступным миром, протекиионизм, продажа различных должностей, званий, наград и т.д. и т.п.) без различения ролей участников преступления и сущностей, воплощающих удовлетворение интересов обеих сторон. По мере широкого ознакомления общества со всякими нарушениями (крайне невнятное обозначение!) в работе должностных лиц (еще одно невнятное обозначение) требуется все большее число точных и кратких обозначений таких конкретных нарушений (видимо, в принципе число их типов конечно). Новые обозначения, однако, либо вовсе не возникают, либо остаются описательными и весьма громоздкими (оборотни в погонах, например, где проясняется лишь принадлежность преступников к силовым структурам), либо архаизируются. Именно тенденция к увеличению контекстуальности действует в современной разговорной речи и в политическом дискурсе.

Противоположную тенденцию являет дискурс в специальных областях (Иомдин и др. 2013). Так, например, спорт как предметная область демонстрирует тенденцию к появлению точных обозначений, пусть и с формальным усложнением: синхронное (художественное) плавание, хоккей на траве, пляжный волейбол, женский футбол. То же самое наблюдаем в обозначениях блюд в ресторанах и даже столовых, в названиях предметов одежды и обуви, где еще четверть века назад русский язык обходился самыми общими обозначениями типа суn (первое) второе - третье, иуба - пальто - плаш - костюм - платье - брюки. Разнообразие жизни ведет к разнообразию именований. Однако эта закономерность действует по-разному в разных сферах жизни (и дискурса!). Если бы современная социология как наука больше интересовалась не предвыборными рейтингами партий и политиков, но стремилась бы понять, в чем (и почему?) наше общество 
начинает разбираться глубже и тоньше, а где - примитивизируется, данные о нынешнем состоянии разных типов русского дискурса, рассмотренные по параметру «контекстуальность», дали бы не просто интересные, но и весьма полезные для самого, мало склонного к рефлексии, общества результаты. Очевидно, что истинно научный дискурс по своей природе также стремится к уменьшению контекстуальности. Рост числа названий разного рода лекарств, необходимость патентного закрепления таких названий, а также процент таких именований, становящихся общеупотребительными, - одно из ярких таких проявлений.

\section{7. Контекстуальность русского языка и общественная практика}

Как кажется, предложенный угол рассмотрения достаточно хорошо известных явлений и фактов, представленных в русском языке, позволяет и поставить принципиальные вопросы, и предложить практические рекомендации.

1. Сопоставление языков по параметру, определяющему соотношение в речевой деятельности формально выраженных и внятных и не выраженных и невнятных компонентов, представляется весьма перспективным. Такой взгляд способен многое прояснить не только в общей проблеме соотношения языка и мышления, но и способствовать изучению конкретных свойств определенных менталитетов и типов поведения. При этом едва ли целесообразно спешить давать оценки «хорошо/плохо» разным типам такого соотношения (Hofstede 2001; Hofstede, Minkov 2010). Замечу лишь, что максимально низкая контекстуальность (что это такое?), конечно же, идеал, к которому следует стремиться, никогда его не достигая, в науке. Однако такое стремление едва ли оправдано в человеческом общении, личном и с помощью разного рода гаджетов, благодаря СМИ, с разными типами участников и т.д. и т.п. Очевидно, что цели, нередко противоположные у производителя и получателя информации, эффективно достигаются здесь благодаря множеству разных характеристик речи, а не благодаря одной-единственной.

Также следует воздержаться от перевода сделанных наблюдений «в цифру», как бы модно это сейчас ни выглядело. Числовое представление качественных характеристик всегда сомнительно, а при размытости самих этих характеристик сомнительно вдвойне (Council of Europe Communications Ref. DC 024, 2019).

В новой лингвистической парадигме современная академическая и университетская русистика сделала резкий крен в направлении культурологии. Это отсутствие конкретных знаний (не путать с возможностью разных проявлений) о способах преодоления ассиметричного дуализма языкового знака не способствует ни научному прогрессу, ни удовлетворению общественных потребностей. Мы не имеем полного набора конкретных алгоритмов для устранения многозначности слов и форм слова, мы часто не умеем раскрывать круг конкретных предметов, явлений, действий и т.д., скрывающихся за гиперонимами, мы не обладаем набором правил, позволяющих в каждом конкретном слове восстановить отсутствующий в тексте, но присутствующий в сознании коммуникантов фрагмент действительности... А если и обращаем внимание на эти обстоятельства, то только как на предмет шуток и анекдотов (Шмелева, Шмелев 2002). А между тем неточное и/или неполное понимание говорящими по-русски текстов на русском 
языке превращается в опасную социальную проблему. Гораздо более опасную, чем нарушение орфографических и/или орфоэпических норм, которое, хотя и создает помехи при коммуникации, обычно не приводит к ложному пониманию со стороны участников коммуникации (Пешковский 1959).

2. Нуждаются в принципиальной коррекции в своей правой части толковые словари русского языка. Речь в данном случае идет не о коррекции количества значений или метаязыка их описания, но о необходимости хоть каким-то образом указывать те типы контекстов (а не просто приводить отдельные примеры), где реализуется то или иное значение. В настоящее время такие общие указания практически отсутствуют, если не считать таковым, например, «в предикативном употреблении».

Как можно предположить на основе сделанных выше наблюдений, человек при рецепции на родном языке не перебирает возможные значения встреченного слова, чтобы затем, погрузившись в контекст, остановиться на каком-то одном из этих значений, как это часто делает, разбирая слово за словом, переводчик письменного текста с неродного языка. По-видимому, сначала реципиент текста на родном языке представляет в общем виде описываемую ситуацию и уже в этом ситуативном контексте семантизирует более или менее протяженные вербальные блоки, именно таким образом уже с помощью вербального контекста преодолевая заложенную в них неоднозначность. При этом здесь возможны разного рода расхождения между результатом деятельности реципиента и замыслом продуцента, что крайне опасно для коммуникации. В настоящем же виде толковый словарь русского языка (и не только русского) очень похож на тест с выбором из предложенных ответов. При этом неясно, и в словаре, и в тесте одинаково, какой же алгоритм действий приводит к выбору из предложенных ответов - правильного. Для словаря - в каждом конкретном употреблении, для теста - единственного среди других, неправильных.

Абсолютно все то же самое относится к описательным классифицирующим грамматикам русского языка от Грамматики Ломоносова до «Русской грамматики» 1980 года.

3. В процессе преподавания русского языка как родного, если цель его преподавания не ограничивать овладением правилами орфографии и пунктуации, следовало бы увеличить число упражнений на 1) разграничение информации формально выраженной и не выраженной, связывая это, например, с опытом импрессионизма в разных видах искусства, 2) добавление в текст необходимой / устранение избыточной, по мнению разных реципиентов, информации, 3) определение в текстах многозначности, расплывчатости, двусмысленности, не преодолеваемой контекстом, и нахождение возможностей для устранения этих характеристик, 4) соотнесение целей реципиента и продуцента информации и возможностей преобразования заданного текста в сторону его большей / меньшей конкретности.

4. При обучении русскому языку как неродному, видимо, следует больше обращаться к прямому методу, к различным разговорникам, давая возможность учащимся запоминать целые блоки слов (и диалогов?), употребительных именно в определенных ситуациях, не оперируя исключительно словом как единицей для 
понимания чужих и построения собственных речевых высказываний. При этом чисто лингвистическое осмысление должно уходить на второй план или может даже отсутствовать.

5. Для общей и частных теорий перевода разные формы и разная степень проявления характеристики «контекстуальность» также требуют большего внимания. В частности, к более или менее строгой обязательности / необязательности некоторых семантических характеристик и вербальных распространений, к построенной на многозначности «игре слов» (и ассоциаций), представленных в одном языке и отсутствующих в другом, к необходимости учитывать неочевидные возможности неоднозначности толкований коррелирующих языковых единиц в языке-базе и в языке-цели.

(C) И.Г. Милославский, 2019 (c) creative

https://creativecommons.org/licenses/by/4.0/

\section{ФИНАНСИРОВАНИЕ И БЛАГОДАРНОСТИ:}

Исследование выполнено при поддержке РФФИ (грант 17-04-00053-ОГН/18).

\section{СПИСОК ЛИТЕРАТУРЫ / REFERENCES}

Алифиренко Н.Ф. Современные проблемы науки о языке. М., 2014. С. 289-313. [Alifirenko, N.F. (2014). Modern problems of the science of language. Moscow, 289-313. (In Russ.)]

Алпатов В.М. История лингвистических учений. М., 2005. C. 130-143. [Alpatov, V.M. (2005). History of linguistic teachings. Moscow, 130-143. (In Russ.)]

Балачандран Н. Степень контекстуальности культуры как фактор информации в межкультурной коммуникации. Мир русского слова. 2016. № 4. [Balachandran, N. (2016). The degree of cultural contextuality as a factor of information in intercultural communication. "The World of the Russian word». No 4. (In Russ.)]

Богданова Л.И. Многозначность и заимствование как когнитивные процессы в современном русском языке // Язык. Культура. Перевод. Коммуникация. Выпуск 2. М., 2008. [Bogdanova, L.I. (2008). Polysemy and borrowing as cognitive processes in modern Russian. Language. Culture Transfer. Communication. Release 2. Moscow. (In Russ.)]

Валгина Н.С. Активные процессы в современном русском языке. М., 2001. [Valgina, N.S. (2001). Active processes in modern Russian. Moscow. (In Russ.)]

Виноградов В.А. Артикль // Лингвистический энциклопедический словарь. М., 1990. [Vinogradov, V.A. (1990). Article. Linguistic Encyclopedic Dictionary. Moscow (In Russ.)]

Виноградов В.В. Русский язык. М., 1972. [Vinogradov, V.V. (1972). Russian language. Moscow. (In Russ.)]

Гордиевская М.Л. Семантика контролируемости/неконтролируемости в русском языке // Язык, культура, коммуникация: изучение и обучение: Материалы III международной научнопрактической конференции. Орел, 2018. [Gordievskaya, M.L. (2018). Semantics of controllability/uncontrollability in the Russian language. Language, culture, communication: study and training: Materials of the III International Scientific Practical Conference. Oryol. (In Russ.)]

Доброхотов А.Л. Новая философская энциклопедия. Институт философии РАН. М., 2010. [Dobrokhotov, A.L. (2010). New philosophical encyclopedia. Institute of Philosophy RAN. Moscow. (In Russ.)]

Добров Б.В., Лукашевич Н.В. Разрешение лексической многозначности на основе тезауруса предметной области. Труды международной конференции «Диалог - 2007». [Dobrov, B.V., 
Lukashevich, N.V. (2007). The resolution of lexical ambiguity based on the thesaurus of the subject area. Proceedings of the international conference "Dialogue - 2007". (In Russ.)]

Зализняк Андрей А. Русское именное словоизменение. М., 1967. [Zaliznyak, Andrei A. (1967). Russian nominal inflection. Moscow. (In Russ.)]

Зализняк Андрей А. Прогулки по Европе. М.; СПб., 2018. [Zaliznyak, Andrei A. (2018). Walking around Europe. Moscow - Saint-Petersburg. (In Russ.)]

Зализняк Анна А. Многозначность в языке и способы ее представления. M., 2006. [Zaliznyak, Anna A. (2006). Polysemy in language and methods of its presentation. Moscow. (In Russ.)]

Иомдин Б.Л. и др. Словарь бытовой терминологии: новые проблемы и новые методы // Компьютерная лингвистика и интеллектуальные технологии. Вып. 12 (19). Т. 1. М., РГГУ, 2013. [Iomdin, B.L. and others (2013). Dictionary of household terminology: new problems and new. Computational linguistics and intellectual technologies. Issue 12 (19). T. 1. Moscow: RSUH. (In Russ.)]

Иомдин Б.Л. Многозначные слова в контексте и вне контекста // Вопросы языкознания. 2014. № 4. [Iomdin B.L. (2014). Many-valued words in context and out of context. Questions of linguistics. No 4. (In Russ.)]

Кобрицов Б.К. Методы снятия семантической многозначности. НТИ серия 2, 2004. № 2. [Kobritsov, B.K. (2004). Methods for removing semantic ambiguity. STI series 2, No 2 (In Russ.)]

Ларина Т.В. Основы межкультурной коммуникации. М., 2017. [Larina, T.V. (2017). Osnovy mezhkul'turnoi kommunikatsii. Moscow. (In Russ.)]

Лотман Ю.М. К проблеме типологии культур. Ереван, 1979. [Lotman, Yu.M. (1979). To the problem of the typology of cultures. Yerevan. (In Russ.)]

Лотте Д.С. Основы построения научно-технической терминологии: вопросы теории и методики. M., 1961. [Lotte, D.S. (1961). Fundamentals of construction of scientific and technical terminology: questions of theory and methodology. Moscow. (In Russ.)]

Ляшевский О.Н. Семантика русского языка. М., 2004. [Lyashevsky, O.N. (2004). The semantics of the Russian language. Moscow. (In Russ.)]

Милославский И.Г. Видовая принадлежность глагола в обеспечении рецептивной и продуктивной речевой деятельности // Изв. РАН СЛЯ, 2015. Том 74. № 1. [Miloslavskiy, I.G. (2015). The species of the verb in the provision of receptive and productive speech activity. Izv. RAN SLYa, Vol. 74. No 1. (In Russ.)]

Милославский И.Г. О принципиальных различиях между русскими грамматиками для рецепции и продукции. Russian Journal of Linguistics, 2018. Vol. 22. № 2. [Miloslavskiy, I.G. (2018). On the fundamental differences between Russian grammars for reception and production. Russian Journal of Linguistics. Vol. 22. No. 2. (In Russ.)]

Ольховская А.И. Полисемия как проблема общей и словарной лексикологии. М., 2015. [Olkhovskaya, A.I. (2015). Polysemy as a problem of general and vocabulary lexicology. Moscow. (In Russ.)]

Падучева Е.В. Неопределенно-личное предложение и его подразумеваемый субъект // Bonpocbl языкознания, 2012. № 1. [Paducheva, E.V. (2012). Indefinitely-personal sentence and its implied subject. Questions of linguistics, No 1. (In Russ.)]

Панов М.В. О некоторых общих тенденциях... // Bonросы языкознания, 1963. [Panov, M.V. (1963). On some general trends ... Questions of linguistics. (In Russ.)]

Пешковский А.М. Объективная и нормативная точка зрения на язык. В кн. Пешковский А.M. Избранные труды. М., 1959. [Peshkovsky, A.M. (1959). Objective and normative point of view on the language. In the book. Peshkovsky A.M. Selected Works. Moscow. (In Russ.)] 
Санников В.3. Русский язык в зеркале языковой игры. М., 1999. [Sannikov, V.Z. (1999). Russian language in the mirror of the language game. Moscow. (In Russ.)]

Солганик Г.Я. Современная языковая ситуация и тенденции развития русского литературного языка // Вестник МГУ, серия 10 «Журналистика», 2010. № 5. [Solganik G.Ya. (2010). Modern linguistic situation and development trends of the Russian literary language. Vestnik $M G U$, series 10 Journalism, No. 5. (In Russ.)]

Соссюр Ф. Курс общей лингвистики. М., 2004. [Saussure, F. (2004). The course of general linguistics. Moscow. (In Russ.)]

Флиер А.Я. Культурология для культурологов. М., 2002. [Flier, А.Ya. (2002). Culturology for cultural studies. Moscow. (In Russ.)]

Шмелева Е.А., Шмелев А.Д. Русский анекдот. Текст и речевой жанр. М., ЯСК, 2002. [Shmeleva, E.A., Shmelev A.D. (2002). Russian anecdote. Text and speech genre. Moscow: YASK. (In Russ.)]

Hall, E. (1990). Understanding cultural differences. Intercultural Press.

Hofstede, G. (2001). Culture's Consequences: International Differences in Work-Related Values, Sage.

Hofstede, G., Minkov, M. (2010). Cultures and Organizations: Software of the Mind. Macgrow-Hill.

Inglehart, R.F. (2018). Cultural Evolution: People's Motivations are Changing, and Reshaping the World. Cambridge University Press.

Navigli, R. (2009). Word Sense Disambiguation: a Survey. ACM Computing Surveys. ACM Press, No 41 (2), 1-69.

Roy, M. (2010). Berko, et al. Communicating. Boston.

\section{Article history:}

Received: 03 March2019

Revised: 24 April 2019

Accepted: 12 May 2019

\section{История статьи:}

Дата поступления в редакцию: 03 марта 2019

Дата принятия к печати: 12 мая 2019

\section{Bionote:}

IGOR G. MILOSLAVSKY - Doctor of Philology, Academician of the International Higher Education Academy of Sciences, Distinguished professor of Lomonosov Moscow State University, Head of the Department of Comparative Analysis of Languages. Research interests: studies of active grammar of the Russian language, creation of special divisions of ideographic grammar of the Russian language, revelation of combinatory possibilities of the units of different level conveying definite nominative contents.

Contact information: e-mail: igormil@hotmail.com

\section{Сведения об авторе:}

ИГОРЬ ГРИГОРЬЕВИЧ МИЛОСЛАВСКИЙ - доктор филологических наук, профессор, заведующий кафедрой сопоставительного изучения языков факультета иностранных языков и регионоведения МГУ, заслуженный профессор МГУ имени М.В. Ломоносова, академик Международной академии. Сфера научных интересов: изучение вопросов активной грамматики русского языка, создание специальных разделов идеографической грамматики русского языка, выявление комбинаторных возможностей единиц различного уровня, выражающих определенное номинативное содержание

Контактная информация: e-mail: igormil@hotmail.com 